\title{
Analysis of the performance of grounding grids buried in heterogeneous soil under impulse current
}

\author{
Amina Djaborebbi, Boubakeur Zegnini, Djillali Mahi \\ Department of Electrical Engineering, Amar Telidji University of Laghouat (UATL), Algeria
}

\begin{tabular}{|c|c|}
\hline Article Info & ABSTRACT \\
\hline & The article presents the analysis of the transient behaviour of grounding grids \\
\hline Received Aug 25, 2020 & $\begin{array}{l}\text { subjected to impulse lightning current. The TLM including mutual coupling } \\
\text { between conductors will be applied. The transient behaviour will be assessed }\end{array}$ \\
\hline Revised Mar 2, 2021 & into complete time domain solution by entombing under homogeneous and \\
\hline Accepted Mar 14, 2021 & $\begin{array}{l}\text { stratified soil. Different simulations carried out altering, the influence of the } \\
\text { grid dimensions, the kind of the ground and the current injection point on the }\end{array}$ \\
\hline Keywords: & $\begin{array}{l}\text { grid voltage and impedance will be presented. Simulation results will be } \\
\text { shown for two extreme cases. The current is going to be injected twice. }\end{array}$ \\
\hline $\begin{array}{l}\text { Grounding grids } \\
\text { Homogeneous soil } \\
\text { Impulse current } \\
\text { Injection point } \\
\text { Mutual coupling }\end{array}$ & $\begin{array}{l}\text { Firstly, in the center of the grid. Secondly, in one cormer of the two } \\
\text { configuration. Comsequently, the lowest transient potential displays in the } \\
\text { grid } 1 \times 1 \text { when the injuction point is in the lower resistivity. Whereas the } \\
\text { better behaviour is shown in the grid } 2 \times 2 \text { when the current is injected at } \\
\text { center point. It is obvious that the suggested simulations are in a good } \\
\text { agreement, with corresponding results of other researchers. }\end{array}$ \\
\hline
\end{tabular}

This is an open access article under the CC BY-SA license.

\begin{abstract}
The article presents the analysis of the transient behaviour of grounding grids subjected to impulse lightning current. The TLM including mutual coupling between conductors will be applied. The transient behaviour will be assessed grid dimensions, the kind of the ground and the current injection point on the grid voltage and impedance will be presented. Simulation results will be shown for two extreme cases. The current is going to be injected twice. Firstly, in the center of the grid. Secondly, in one cormer of the two configuration. Comsequently, the lowest transient potential displays in the better behaviour is shown in the grid $2 \times 2$ when the current is injected at agreement, with corresponding results of other researchers.
\end{abstract}

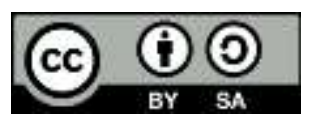

\section{Corresponding Author:}

Amina Djaborebbi

Department of Electrical Engineering

Amar Telidji University of Laghouat (UATL), Algeria

Email: a.djaborebbi@lagh-univ.dz

\section{INTRODUCTION}

Optimization is to improve the grounding systems a so as to protect surroundings people in the grounded installations with low cost [1]. The performance of grounding system under power frequency current is not well understood [1]. The act of this system is changed under impulse current [2]. This makes the behaviour of grounding systems an objective for different investigations, and which have been improved by several simulations and practical tests cited as follow: Ramlee et al. [3] have studied the use of multiple grounding points on the lightning phenomenon. Azmi et al. [4] have improved the grounding system impedance by adding enhancement materials in the surrounding of the studied electrode. Parise et al. [5] have studied the efficiency of grounding system safety by studying the step/touch voltages in the studied system. The first method is known by Antenna theory which tendsto solve Maxwell's electromagnetic field equations either by method of moments or by finite difference time domain [6-8]. Its main shortcoming consists in the long calculation time. Visacro [9] has appllied another approach namely hybrid electromagnetic method. Transient potential and the variation of grounding system impedance in function of frequency. The second method consists in solving Maxwell equations using finite element methods as made by Nekhoul et al. [1011], by Qamar et al. [12-13] and by Akbari et al. [14]. This method requires a long time of calculation with a powerful process calculation [15]. Hasni et al. [16] have used COMSOL to study the effect of concrete orientation in grounding system by FEM. As main result, the full concrete is the best orientation of concrete design to be employed at the grounding systems since it generates a low electric field compared to the other concrete orientation. The third approach, the simplest in the calculation method for the grounding grids 
systems, is based in transmission line approach of grounding grid and could be treated as well as circuit models [17]. Seixas and Kurokawa [18] have proposed electrical grounding systems model which could be simulated directly in the time domain using conventional software such as the alternative transient program (ATP).

The grounding grids hasn't been studied with the TLM. Several parameters have been proposed for the characterization of grounding system transient behaviour. In lightning protection, many terms are used as like "impulse resistance", "impulse impedance"... The transient analysis of grounding systems may contains the transient impedance, $v(t) / i(t)$ peak voltage to peak current $V_{p} / I_{p}$ and $V\left(t_{I_{P}}\right) / I_{p}[19]$.

In the present investigation, we use the TLM method to transient analysis of a grounding grid buried in homogeneous and stratified soil subjected to lightning impulse current. We continue the study of the transient behavior that we have already begin with our recent paper [20], in which we have studied the economic optimization of copper conductor to obtain the best transient response. As main results of the precedent paper, we have obtained that the increasing of conductor paths leads to improve the transient response. In order to validate the behaviour of grounding systems the knowledge of their performance over a wide range of frequencies is required. The new version of this investigation is basedon the study of transient behavior of two simple configurations emtomd under homogeneous and heterogeneous soil, in order to evaluate simultaneously the impact of increasing of conductor paths and heterogeneity of the soil on the transient behavior. For each studied configuration; the transient potential and impedance obtained were displayed, with considering a different point of injection for such case. Certain parameters of yhe impulse of the grounding grids were studied to detect the lower potential transient.

Our article presents the transient study of grounding grids according to the next organization: In the second section we have presented our used transmission line model, with introducing the principal changings which have been added to include mutual coupling phenomena, and we present the impedances relation which have been determined for each studied configuration. The third section is composed of several parts: in the first one we have validated our grounding grids simulation for homogeneous soil by comparing with other studies and we present the transient impedance, after that we have simulated the transient response of grounding grids buried in stratified soil. In the last part, many injection points have been considered and the transient impedance has been determined. The fourth section summanzes most findings and essencail comments.

\section{RESEARCH METHOD}

Each grounding conductor is divided in several sections presented in Figure 1 for modeling the transmission line of grounding systems the wavelength of this current $\lambda$ is able to be determined by:

$$
\lambda=\frac{1}{f \sqrt{\frac{\mu_{m} \varepsilon_{m}}{2}\left(\sqrt{1+\frac{1}{(2 \pi f)^{2} \rho_{m}^{2} \varepsilon_{m}^{2}}}+1\right)}}
$$

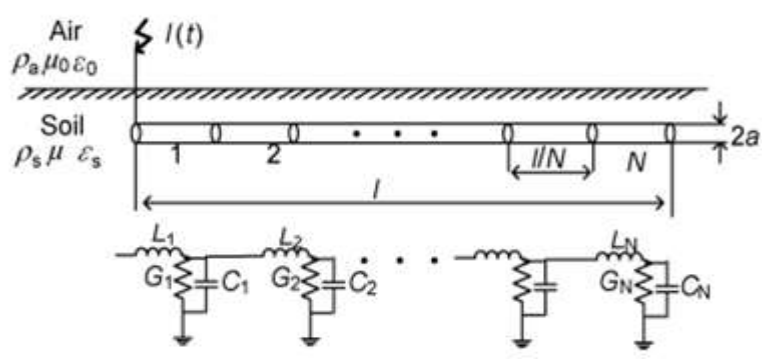

Figure 1. Transmission Line Model [13]

To validate our TLM use to study the transient behaviour, every segment length much be smaller than one tenth of wavelength $(\Delta \mathrm{l} \ll \lambda / 10)$. The following formulas represent parameters for each segment of the grownding systems [21]:

$$
R=\rho_{s} \frac{4 \Delta l}{\pi D^{2}}
$$




$$
\begin{aligned}
& L=\frac{\mu \Delta l}{2 \pi}\left(\ln \left(\frac{2 l}{\sqrt{h D}}\right)-1\right) \\
& C=2 \pi\left(\varepsilon_{0} \varepsilon_{r}\right) \frac{\Delta l}{\ln \left(\frac{2 l}{\sqrt{h D}}\right)-1} \\
& G=\frac{2 \pi}{\rho_{s}} \frac{\Delta l}{\left(\ln \left(\frac{2 l}{\sqrt{h D}}\right)-1\right)}
\end{aligned}
$$

In our simulation, we have treated the transmission line method in time domain. For injected current Ie in transmission line between points $\mathrm{i}$ and $\mathrm{j}$ of grounding conductor, the differential equations of potentials (Ui) and currents (Iij) (which presenting the potentials and currents along the electrode) as presented in (6)(8):

$$
\begin{aligned}
& \frac{d U_{i}}{d t}=\frac{2}{c} I_{e}-\frac{G}{C} U_{i}-\frac{2}{c} I_{i j} \\
& \frac{d I_{i j}}{d t}=\frac{1}{L} U_{i}-\frac{R}{L} I_{i j}-\frac{1}{L} U_{j} \\
& \frac{d U_{j}}{d t}=\frac{2}{c} I_{i j}-\frac{G}{C} U_{j}
\end{aligned}
$$

these equations and the other ones of grounding electrode are solved by using iterative methods according to the next algorithm as shown in Figure 2.

Grounding grids contains several interconnected copper conductors. These two conductors are said to be inductively and capacitively coupled, in addition a mutual conductance exists Figure 3 . The parameters of mutual coupling, mutual capaticance $\mathrm{Cm}$, mutual conductance $\mathrm{Gm}$, and mutual inductance $\mathrm{Lm}$ are defined as next [22-23]:

$$
\begin{aligned}
& C_{m}=\frac{2 \pi \varepsilon_{0} \varepsilon_{r}}{\ln (1 / D)} \\
& G_{m}=\frac{C_{m}}{\rho_{s} \varepsilon} \\
& L_{m=\frac{\mu}{2 \pi}} \ln \left(\frac{1}{D}\right)
\end{aligned}
$$

different indices are used to estimate grounding systems impulse performance [24-25]. These parameters generally relate the potential of an electrode to the injected current. The transient injected current, potential and input impedance for a grounding system are presented in Figure 5. The "impulse impedance" is the most commonly used parameter for lightning protection system, defined by the ratio of potential maximum $V_{P}$ to the current maximum $I_{p}$.

$$
Z_{1}(t)=\frac{V_{p}}{I_{p}}
$$

The impedanceof the impulse is used to evaluate the potential of the impulse current grounding system. The second parameter consists in the ratio of potential obtained at the moment when the current reach the peak value $v\left(t_{I_{p}}\right)$ to the current peak value $I_{p}$. Such parameter shows the predominance of resistive effects on the transient behaviour of grounding system [26-28]. The last parameter is the ratio of potential peak $V_{P}$ to the current value when the potential gets it highest value $i\left(t_{V_{P}}\right)$. This parameter may estimate the maximum potential since it has higher value than the above impedances [29].

$$
\begin{aligned}
& Z_{2}=\frac{v\left(t_{I_{p}}\right)}{I_{p}} \\
& Z_{3}=\frac{V_{P}}{i\left(t_{V_{P}}\right)}
\end{aligned}
$$




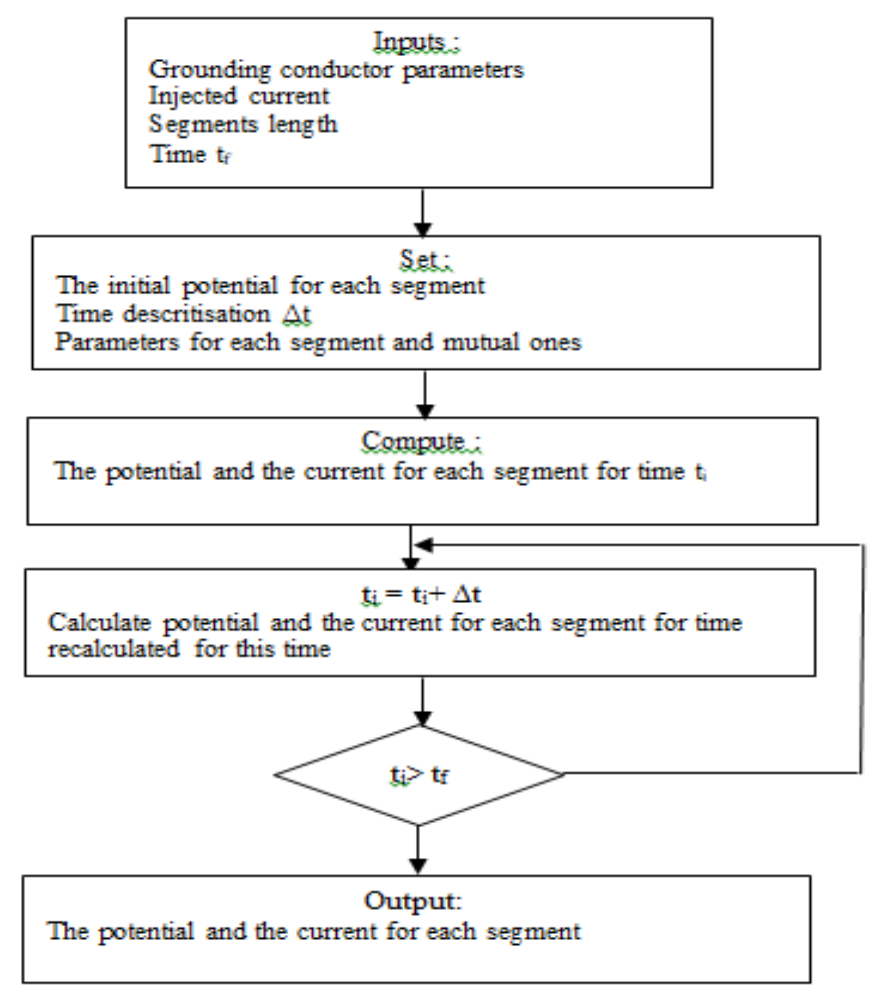

Figure 2. The used Algorithm to calculate the transient potential of grounding grid

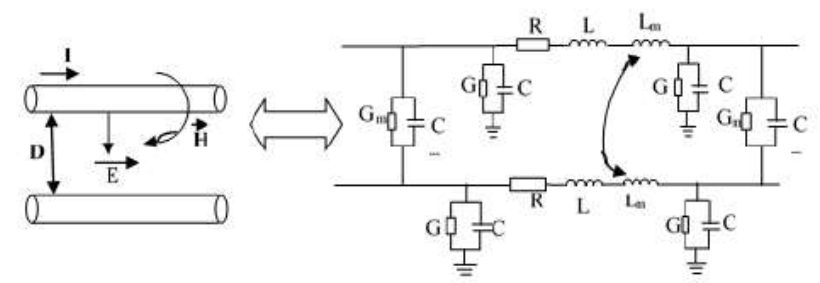

Figure 3. Mutual coupling between parallel conductors

\section{RESULTS AND DISCUSSION}

\subsection{Simulation validation}

Two configurations were simulated using our TLM model shown in Figure 4 to validate our TLM simulation. The radius of the conductor is $7 \mathrm{~mm}$, both grounding grids have been buried at a depth $0.5 \mathrm{~m}$ in uniform soil of $\rho_{s}=1000 \Omega m$ and $\varepsilon_{r}=9$ [2]. The injected current is $i(t)=1\left(e^{-27000 t}-e^{-5600000 t}\right)$ shown in Figure 4. The obtained results by [2] using ATP-EMTP for these configurations are shown in Figure 5.

Our obtained results are presented in Figure 6 the transient potential is presented on the Figure 6(a) and the transient impedance is presented on the Figure 6(b). We note that we have present the transient potentials and impedances in the time range $[0,5]$ to show the important variations in the transient period of the studied grounding system. When comparing the transient potentials in the Figure 6(a) with those presented in the Figure 5, we observe a good accordance between our TLM results with those obtained by [2] using ATP-EMTP. Because of the calculation procedure a brief difference has been appeared. We notice that the transient potential of the $2 \times 2$ grid has lower peak, but the impulse form is greater than that of the $1 \times 1$ grid. From Figure 6(b): the transient impedance before $1 \mu$ s dramatically increases until the oscillations in grid transient impedance $2 \times 2$ are higher than those of grid $1 \times 1$ hitting the maximum value $(80 \Omega)$ then decrease. From $1 \mu \mathrm{s}$, the impedance given a constant value $(54,1 \Omega$ for $1 \times 1$ grid and $17,3 \Omega$ for grid2x 2$)$ which corresponds to low frequency resistance. Table 1 present the impulse parameters Z1, Z2 and Z3 calculated according to $(12,13$ and 14) from the obtained results appearing in Figure 6. 
The results show that for homogeneous soil, no difference between the impedances Z1, Z2 and Z3 for the grid $1 \times 1$. For the grid $2 \times 2$, the difference between these three parameters is clear. So, the behaviour for the grid 1x1 converges to the resistive behaviour. For the grid 2x2, the inductive behaviour appears since the variations of the transient impedance are accentuated but an observable decrease has been obtained for $\mathrm{Z} 1$ and $\mathrm{Z} 2$.

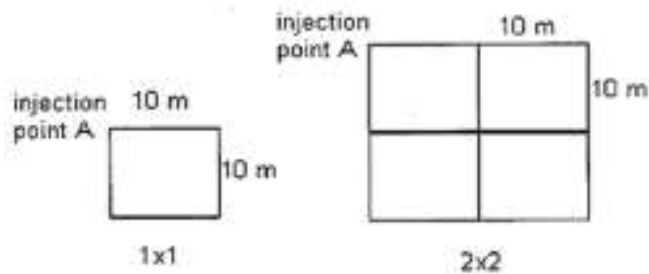

Figure 4. The different configurations [2]

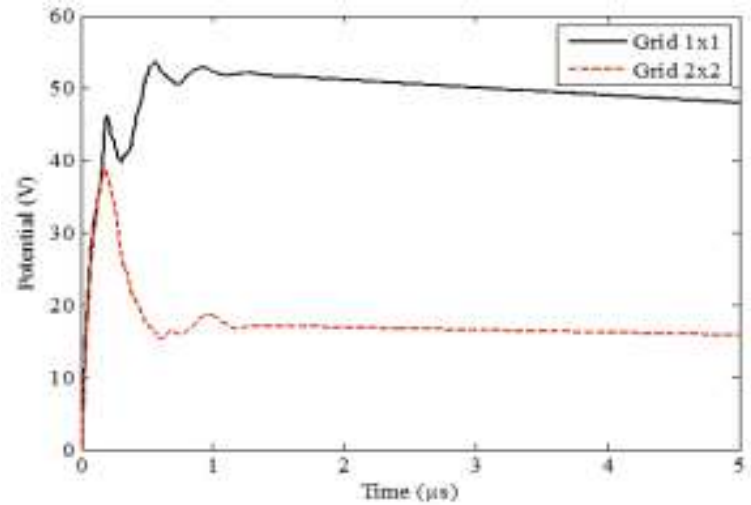

(a) Transient potential

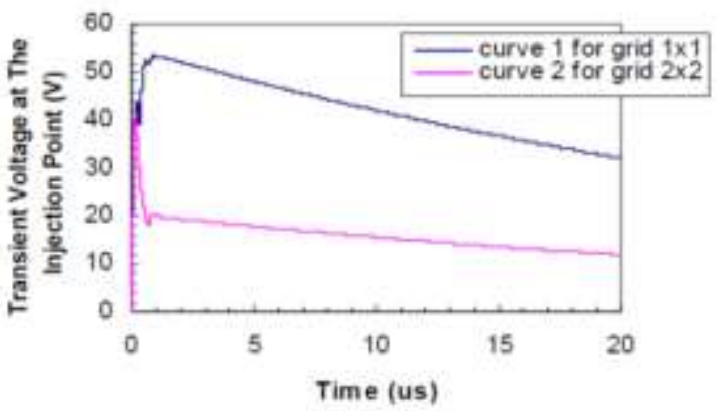

Figure 5. The transient potential obtained using ATP-EMTP by [2]

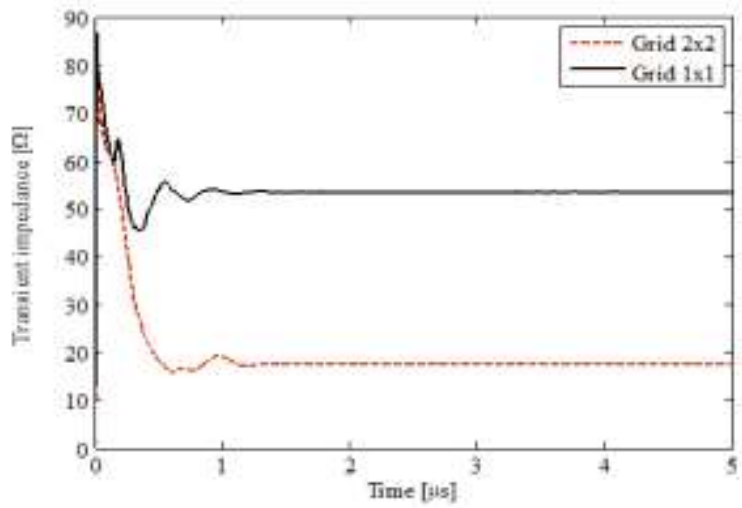

(b) Transient impedance

Figure 6. The obtained results for configurations presented in Figure 4

Table 1. The impulse parameters for grids $1 \times 1$ and $2 \times 2$

\begin{tabular}{llll}
\hline & $\mathrm{Z}_{1}(\Omega)$ & $\mathrm{Z}_{2}(\Omega)$ & $\mathrm{Z}_{3}(\Omega)$ \\
\hline Grid 1x1 & 53.59 & 52.92 & 56.41 \\
Grid 2x2 & 38.56 & 18.27 & 55.08 \\
\hline
\end{tabular}

\subsection{Heterogeneous soil}

Following validation of our TLM grid simulation, we propose to assrss the transient potential of grids buried in vertically stratified soil as presented in Figure 7. The 1x 1 grid configuration has been buriedas seen in Figure 7 in heterogeneous soil. The first soil is defined by the following soils: $\rho_{s}=1000 \Omega \mathrm{m}$ and $\varepsilon_{r}=9$, and $\rho_{s}=200 \Omega m$ and $\varepsilon_{r}=40$. Two points $\mathrm{A}$ and $\mathrm{B}$ of the grounding device present in Figure 8 indicate the same pulse present.

The findings in Figure 8(a) suggest that the lowest peak value of transient potential is reached by injecting the lower resistivity side, which is why injecting in the lower resistivity side of the corner provides the desired potential. As the lower resistivity side injection gives the lowest potential, the transient impedance is lower. Otherly we say that injection at the choose of corner in existing in lower resitivity side is a solution to obtain a reduced transient impedance. The parameters $\mathrm{Z} 1, \mathrm{Z} 2$ and $\mathrm{Z} 3$ for the three studied configurations (homogeneous and heterogeneous soil) are present in Table 2. 


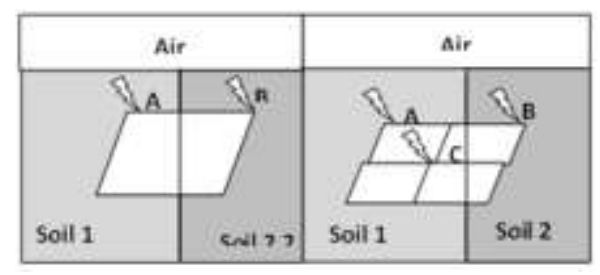

Figure 7. The different configurations

Table 2. Impulse parameters for grids $1 \mathrm{x} 1$ evaluated in Figure 8

\begin{tabular}{cccc}
\hline & $\mathrm{Z}_{1}(\Omega)$ & $\mathrm{Z}_{2}(\Omega)$ & $\mathrm{Z}_{3}(\Omega)$ \\
\hline Homogeneous soil & 53.59 & 52.92 & 56.41 \\
Injection point A & 30.35 & 17.77 & 49.75 \\
Injection point B & 17.47 & 17.50 & 18.01 \\
\hline
\end{tabular}

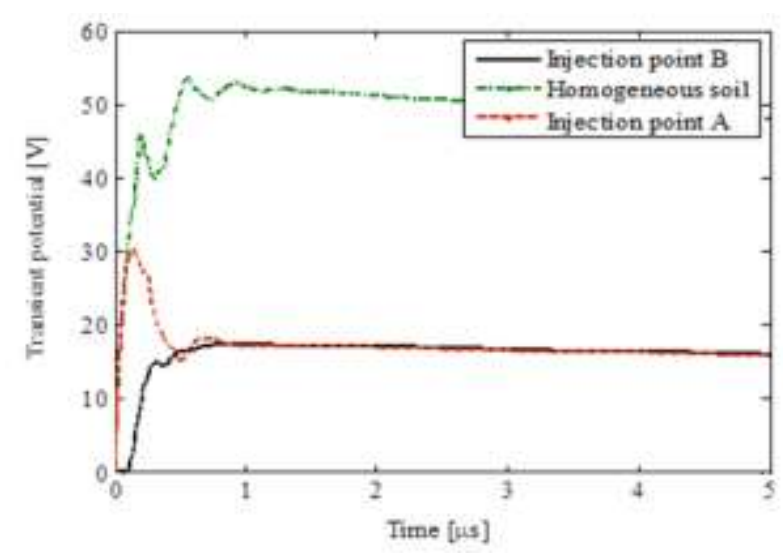

(a) Transient potential

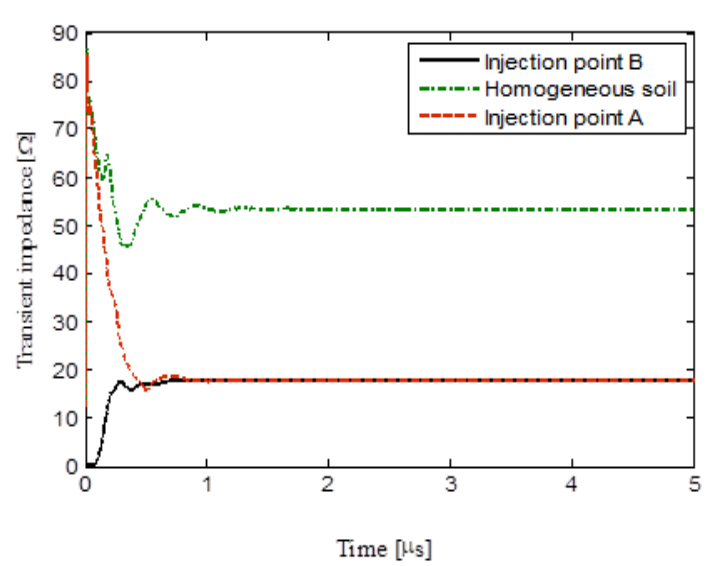

(b) Transient impedance

Figure 8. Results obtained for 1x1 grid buried in uniform and heterogeneous soils

For injection point A; an obsevable difference between the parameters $\mathrm{Z} 1, \mathrm{Z} 2$ and $\mathrm{Z} 3$ because of the impulse form of transient potential. For the injection point B; the parameters Z1, Z2 and Z3 are around the same level, which shows the resistive behaviour for this configuration. The results shown in Table 2 prouves that the injection at the low soil resistivity side gives the lowest impulse parameters values.

When the same impulse current is presented, the grid 2x2, presented in Figure 7 was evaluated. Soil 1 features are: $\rho s=1000$ and $\epsilon r=9$, and for soil 2 features: $\rho s=200$ and $\epsilon r=40$. Three separate points $A, B$, and $C$ were inserted into the impulse current. The results obtained at injection point are can be seen in Figure 9; Figures 9(a) shows the transient potential and Figure 9(b) shows transient impedance.

For all of the cases, an oscillation of transient potential is observed, the results obtained in Figure 9(a). The most signification is the potential achieved by injecting point A, and the potential archieved by injecting point $\mathrm{B}$. The lowest values for transient potential results were obtained when injected under $\mathrm{C}$. All the potential is stabilized after these oscillations and gives the same response. The injection in the middle of the grid therefore gives the lowest transient maximum value.

The results of Figure 9(a) show that when injecting in A, maximum transient impedance was archieved when the grids buried into uniforme soil reached the peak value. The injection in point B gives a lower value for a transient impedance. During the injection at the middle of the grounding grid, the least impedance values were obtained. The parameters $\mathrm{Z} 1, \mathrm{Z} 2$ and $\mathrm{Z} 3$ for the three studied configurations for $2 \times 2$ grid (uniform and heterogeneous soil) are shown in Table 3.

For the injection point A; an obsevable difference between all of the parameters Z1, Z2 and Z3, note that the values of $\mathrm{Z} 1$ and $\mathrm{Z} 3$ are close to those obtained for uniform soil. For the injection point $\mathrm{B}$; a decrease in the value of $\mathrm{Z} 1$ and $\mathrm{Z} 3$ has been observed, but the difference $\mathrm{Z} 1$ and $\mathrm{Z} 2$ and $\mathrm{Z} 3$ between still significant. For the injection point $C$; a slight decrease in the value of $\mathrm{Z} 1$ and $\mathrm{Z} 2$ has been noted, but it gives low values 
for all of the parameters Z1, Z2 and Z3. The results shown in Table 3 prouves that lowestimpulse parameters values are given by a $2 \times 2$ grid injection in the middle. All of the data linked to the potential are presented in the Table 4.

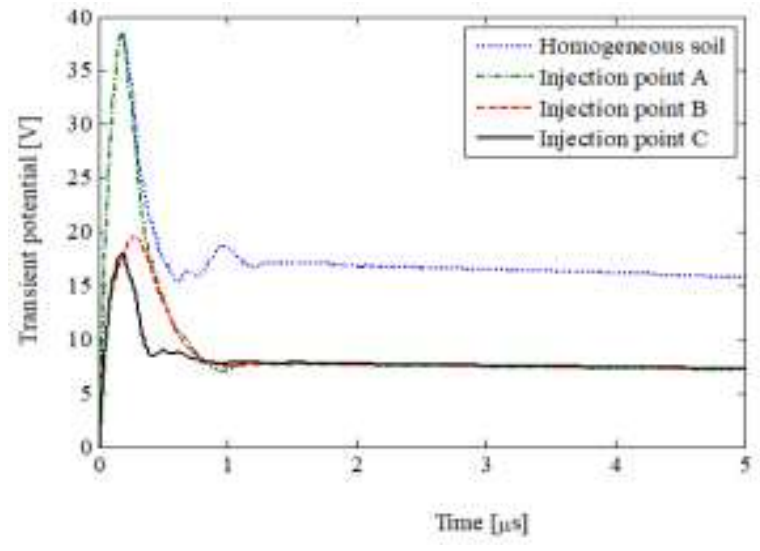

(a) Transient potential



(b) Transient impedance

Figure 9. Results obtained for $2 \times 2$ grid buried in uniform and heterogeneous soils

Table 3. Impulse parameters for grids $2 \times 2$ evaluated in Figur 9

\begin{tabular}{cccc}
\hline & $\mathrm{Z}_{1}(\Omega)$ & $\mathrm{Z}_{2}(\Omega)$ & $\mathrm{Z}_{3}(\Omega)$ \\
\hline Homogeneous soil & 38.56 & 18.27 & 55.08 \\
Injection poinr A & 38.48 & 8.10 & 56.58 \\
Injection point B & 19.61 & 8.10 & 23.62 \\
Injection point C & 18 & 7.90 & 25.71 \\
\hline
\end{tabular}

Table 4. Data linked with potential graphs. Transient potential [V]

\begin{tabular}{cccccccc}
\hline Time $[\mu \mathrm{s}]$ & $\begin{array}{c}1 \times 1 \text { grid }[\mathrm{V}] \\
\text { homogeneous } \\
\text { soil }\end{array}$ & $\begin{array}{c}2 \times 2 \text { grid }[\mathrm{V}] \\
\text { homogeneous } \\
\text { soil }\end{array}$ & $\begin{array}{c}1 \times 1 \text { grid }[\mathrm{V}] \\
\text { Injection } \\
\text { point A }\end{array}$ & $\begin{array}{c}1 \times 1 \text { grid }[\mathrm{V}] \\
\text { Injection } \\
\text { point B }\end{array}$ & $\begin{array}{c}2 \times 2 \text { grid [V] } \\
\text { Injection } \\
\text { point A }\end{array}$ & $\begin{array}{c}2 \times 2 \text { grid [V] } \\
\text { Injection } \\
\text { point B }\end{array}$ & $\begin{array}{c}2 \times 2 \text { grid [V] } \\
\text { Injection } \\
\text { point C }\end{array}$ \\
\hline 1 & 53 & 18 & 17 & 17 & 10 & 10 & 10 \\
2 & 50 & 17 & 16 & 16 & 9,3 & 9.3 \\
3 & 49 & 16 & 15 & 15 & 8.4 & 7.4 \\
4 & 48 & 15 & 14 & 14 & 7.4 & 7.4 \\
5 & 45 & 14 & 13 & 13 & 6.5 & 6.4 & 6.4 \\
\hline
\end{tabular}

\section{CONCLUSION}

In this paper we presented evaluated the transient potential and impedance of simple grounding systems. The TLM has been used with incorporate mutual interconnection between grounding conductors. Many parameters have been changed in the simulations namely: heterogeneity of soil, the grounding grid configuration, the current injection point. The potential and transient impedance have been calculated for each simulation. The obtained results showed that when the injection point is placed on the lower resistivity side of the $1 \times 1$ grid, the lowest transient potential is obtained. When injecting in the center point of the $2 \times 2$ grid, the lowest transient potential vlues are obtained. The validity of our TML results was tested by comparing the behavior of grounding grids subjected to impulse current in simulation on simple buried structures with some other calculations done with the ATP-EMTP software package, and our results have showed a good satisfactory. The present paper has been limited to the study of the simple grounding grids as an effective solution to replace grounding electrodes when the space proposed for the grounding is limited, and this has been already proved in our previous work. The transient responses obtained present that stratified soil have an important impact on the transient behavior, which is more important when comparing to the injection point impact. The next paper will be devoted to developing these studied configurations to study the behavior of wind turbine grounding systems which some similarities with the configurations have studied in this work. 


\section{REFERENCES}

[1] "IEEE guide for safety in ac substation grounding," IEEE Standard 80, New York 2000, doi: 10.1109/IEEESTD.2015.7109078.

[2] Yaqing Liu, MihaelZitnik, and Rajeev Thottappillil, "An Improved Transmission-Line Model of Grounding System," IEEE Transactions on Electromagnetic Compatibility, vol. 43, no. 3, pp. 348-355, august 2001, doi: 10.1109/15.942606.

[3] N. Asrina Ramlee, N. A. Ahmad, Z. A. Baharudin, A. R. Mohamed, "High-Speed video observations on fork lightning events in Malaysia," Indonesian Journal of Electrical Engineering and Computer Science (IJEECS), vol. 19, no. 3, pp. 1620-1625, September 2020, doi: 10.11591/ijeecs.v19.i3.pp1620-1625.

[4] A. Azmi, N. A. Ahmad, L. K. Yiew, Z. Abdul-Malek, "The use of enhancement material in grounding system: a review," Indonesian Journal of Electrical Engineering and Computer Science (IJEECS), vol. 13, no. 2, pp. 453460, February 2019, doi: 10.11591/ijeecs.v13.i2.pp453-460.

[5] G. Parise, L. Parise, L. Martirano, "Intrinsically Safe Grounding Systems and Global Grounding Systems," IEEE Transactions on Industry Applications, vol. 54, no. 1, pp. 25-31, Jan.-Feb. 2018, doi: 10.1109/TIA.2017.2743074.

[6] L Grecev, "Lightning Surge Efficiency of Grounding Grids, “ IEEE transactions on power delivery, vol. 26, no. 3, july 2011, doi: 10.1109/TPWRD.2010.2102779.

[7] D. Poljak, S. Sesnic, S. V. Tkachenko, K. El KhamlichiDrissi, and K. Kerroum, "Time Domain Analysis of the Horizontal Grounding Electrode: Antenna theory approach versus transmission line approximation," Proc. of the 2014 International Symposium on Electromagnetic Compatibility (EMC Europe 2014), Gothenburg, Sweden, pp. 181-185, September 1-4, 2014, doi: 10.1109/EMCEurope.2014.6930899.

[8] W. Xiong, F. P. Dawalibi, and A. Selby, "Frequency Response of Substation Ground Systems Subject to Lightning Strikes," GIGRE International Symposium, Power System Electromagnetic Compatibility, Switzerland, Lausanne, pp. 100-06, 1993, doi: 10.11591/ijece.v6i1.9356.

[9] Visacro, "A comprehensive approach to the grounding response to lightning currents", IEEE Trans. Power Del., vol. 22, no. 1, pp. 381-386, Apr. 2007, doi: 10.1109/TPWRD.2006.876707.

[10] B. Nekhoul, C. Guerin, P. Labie, G. Meunier, R. Feuillet, and X. Brunotte, "A Finite Element Method for Calculating the Electromagnetic Fields Generated by Substation Grounding Systems," IEEE transactions on magnetics, vol. 31, no. 3, pp. 2150-2153, may 1995, doi: 10.1109/20.376472.

[11] B. Nekhoul, P. Labie, F.X. Zgainski, G. Meunier, F. Morillon, and S. Bourg, "Calculating the Impedance of a Grounding System," IEEE Transactions on Magnetics, vol. 32, no. 3, pp. 1509-1512, 1996, doi: 10.1109/20.497536.

[12] Aamir Qamar, Yang Fan, He Wei, Ammad Jadoon, Muhammad Zeeshan Khan, and Xu Naidong, "Topology Measurement of Substation's Grounding Grid by Using Electromagnetic and Derivative Method" Progress In Electromagnetics Research B, vol. 67, pp. 71-90, May 2016, doi: 10.2528/PIERB16030701.

[13] Aamir Qamar, Nadir Shah, Zeeshan Kaleem, Zahoor Uddin, and Farooq A. Orakzi, "Breakpoint Diagnosis of Substation Grounding Grid Using Derivative Method," Progress In Electromagnetics Research M, vol. 57, pp. 7380, May 2017, doi:10.2528/PIERM17020603.

[14] M. Akbari, K. Sheshyekani, and M. R. Alemi, "The Effect of Frequency Dependence of Soil Electrical Parameters on the Lightning Performance of Grounding Systems," in IEEE Transactions on Electromagnetic Comptibility, vol. 55, no. 4, pp.739-746, Aug. 2013, doi: 10.1109/TEMC.2012.2222416.

[15] B. Nekhoul, D. Poljak, D. Sekki, D. Cavka, B. Harrat, K. Kerroum, and K. El KhamlichiDrissi, "An Efficient Transient Analysis of Realistic Grounding Systems: Transmission Line Versus Antenna Theory Approach," Engineering Analysis with Boundary Elements vol. 48, pp. 14-23, 2014, doi: 10.1016/j.enganabound.2014.06.002.

[16] N. A. S. Hasni, S. N. Md Arshad, A. Md Ariffen, N. H. Halim, W. C. Leong, M. I. F. Romli, and O. Abu Bakar, "Effect of Concrete Orientation as an Enhancement Material in Grounding System," 2nd Joint Conference on Green Engineering Technology \& Applied Computing 2020, ui.adsabs.harvard.edu/link_gateway/2020MS\&E..864a2163A/doi:10.1088/1757-899X/864/1/012163.

[17] Daniel S. Gazzana, Guilherme A. D. Dias, Roberto C. Leborgne, Arturo S. Bretas, Marcos Telló, Dave W. P. Thomas, Christos Christopoulos, "Novel Formulation to Determine the Potential on the Soil Surface Generated by a Lightning Surge," IEEE Transactions On Magnetics, vol. 52, no. 3. March 2016, doi: 10.1109/TMAG.2015.2486958.

[18] Claudiner Mendesde Seixas Sérgio Kurokawa, "Using circuit elements to represent the distributed parameters of a grounding system under lightning strokes,“ Electric Power Systems Research, vol. 172, pp. 213-220, July 2019, doi: 10.1016/j.epsr.2019.03.013.

[19] M. Mokhtari, Z. Abdul-Malek and Z. Salam, "An Improved Circuit-Based Model of a Grounding Electrode by Considering the Current Rate of Rise and Soil Ionization Factors," IEEE Transactions On Power Delivery, vol. 30 , no. 1, pp. 211-219. February 2015, doi: 10.1109/TPWRD.2014.2347283.

[20] Djaborebbi Amina, Zegnini Boubakeur, Seghier Tahar, and Mahi Djillali, "Evaluation and Performance of Grounding Grids Buried in Soil Under Impulse lightning Current,“ The First International Conference on Communications, Control Systems and Signal Processing. 16-17 March 2020, El-Oued, Algeria, doi: 10.1109/CCSSP49278.2020.9151549.

[21] N. Harid, H. Griffiths, S. Mousa, D. Clark, S. Robson, and A. Haddad, "On the Analysis of Impulse Test Results on Grounding Systems," IEEE Transactions On Industry Applications, vol. 51, no. 16, pp. 5324-5334, November/December 2015, doi: 10.1109/TIA.2015.2442517.

[22] Sunde ED, "Earth Conducting Effects in Transmission Systems,” New York, N. Y.: Dover publications, Inc.; 1968. 
[23] A. P. SakisMeliopoulos, "Power grounding systems and transients: An introduction," Library of congress electrical and Computer Engineering series, New York, Marcel Dekker.Inc. 1988.

[24] Jinliang He, Rong Zeng, and Bo Zhang, "Methodology and Technology for Power System Grounding," John Wiley \& Sons Singapore Pte. Ltd. Department of Electrical Engineering, Tsinghua University, China (2013).

[25] Leonid Grcev and Marjan Popov, "On High-Frequency Circuit Equivalents of a Vertical Ground Rod," IEEE Transactions on Power Delivery, vol. 20, no. 12, pp. 1598-1603, April 2005, doi: 10.1109/TPWRD.2004.838460.

[26] Amina Djaborebbi, Boubakeur Zegnini, Tahar SeghierHamza Gueffaf, and Djillali Mahi, "Economic optimization of copper conductor for transient response of grounding system," $5^{\text {th }}$ international conference on advances in mechanical engineering, Istanbul 2019, 17-19 December 2019.

[27] L. Duan, B. Zhang, J. He, L. Xiao, and L. Qian, "Experimental Study on Transient Characteristics of Grounding Grid for Substation," In Proceedings of the 33rd International Conference of Lightning Protection (ICLP), Estoril, Portugal, 25-30 September 2016, doi: 10.1109/ICLP.2016.7791392.

[28] A. Etobi, N. Mohamad Nor, S. Abdullah, M. Othman, "Characterizations of a Single Rod Electrode under High Impulse Currents with Different Polarities," In Proceedings of the 1st IEEE International Conference on Electrical Materials and Power Equipment (ICEMPE), Xi' an, China, 14-17 May 2017, doi: 10.1109/ICEMPE.2017.7982148.

[29] C. Yu, Z. Fu, G. Wu, L. Zhou, X. Zhu, M. Bao, "Configuration detection of substation grounding grid using transient electromagnetic method", IEEE Trans. Ind. Electron. 2017, vol. 64, pp. 6475-6483, doi: 10.1109/TIE.2017.2682033.

\section{BIOGRAPHIES OF AUTHORS}

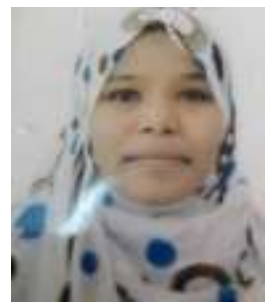

Djaborebbi Amina received her licence Diploma in 2012, and she received the master's degree in 2014 all in Industrial Electrotechnics from the Electrical Engineering department in the University of Ouargla, Algeria. PhD student in the fourth year since 2015 in Materials and systems engineering, working on the theme entitled 'Study of the dynamic behavior of the earthing system under a lightning disturbance-Application coordination of isolation and EMC'. e-mail address: djaborebbiamina@gmail.com

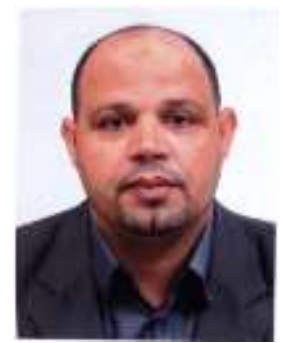

Boubakeur ZEGNINI was born in Laghouat, Algeria on January 25, 1968. He received the Dipl. Eng. Degree in electrical engineering from the ENSET of Laghouat (Algeria) in 1991, the M.Sc. degree from the institute of Electrical Engineering, University Center of Laghouat (Algeria) in 2001. He received the $\mathrm{PhD}$ degree in electrical engineering from Mohammed Boudiaf Science and Technology University of Oran-USTMB Oran-(Algeria) in 2007. He is full Professor at the University of Amar Telidji, in Laghouat (Algeria). His research interests concern: Material characterization, Insulation materials, High Voltage, Modelling, Simulation, Artificial Intelligence, and Power Systems. e-mail address: b.zegnini@lagh-univ.dz

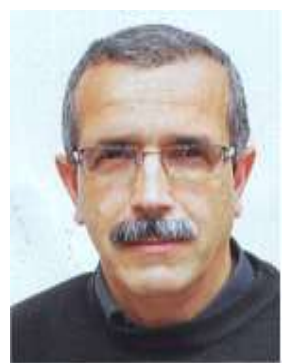

Djillali Mahi was born in Tiaret (Algeria), on June 25, 1959. He graduated the University of Science and Technology, Faculty of Electrical Engineering in Oran (Algeria), in 1982. The DrIng degree from university of Paul Sabatier in Toulouse (France), in 1986. He received the PhD degree in electrical engineering from the University of Djillali Liabes of Sidi Belabbes (Algeria), in 2002. He is full Professor at the University of Amar Telidji, in Laghouat (Algeria). His research interests concern: High voltage materials, power electronics, electric machines, and thermal plasma. e-mail address: d.mahi@lagh-univ.dz 